\title{
Somatic Hybridization of Citrus with Wild Relatives for Germplasm Enhancement and Cultivar Development
}

\author{
Jude W. Grosser ${ }^{1}$ and Frederick G. Gmitter, Jr. ${ }^{2}$ \\ Citrus Research and Education Center, IFAS, University of Florida, 700 Experiment Station Road, Lake \\ Alfred, FL 33850
}

Publicity regarding the loss of existing genetic resources because of human activity in the centers of plant, origin and diversity has stimulated efforts to collect and maintain germplasm in international genebank networks (Poopathy, 1986). The problem is particularly acute for Citrus and related genera because government-sponsored land development programs are destroying the natural habitat of many Citrus spp., and relatives. The International Board of Plant Genetic Resources (IBPGR) [with liaison to the United Nation's Food and Agricultural Organization (FAO)] is negotiating with the Univ. of Malaysia to set up a genebank network for $\mathrm{Cit}$ rus (Poopathy, 1986). Justification and impetus for this program may be provided by the abundance of economically important traits (e.g., tolerance to biotic and abiotic stress, horticultural! characteristics and performance, etc.) that can be found among Citrus spp. and related genera. For such programs to be successful, however, technology must be available to maximize the use of the collected germplasm.

The use of somatic hybridization to obtain wild germplasm for woody fruit tree improvement is discussed in this article, using Citrus as a model. Recovery of intergeneric somatic hybrid plants produced between sexually incompatible Citrus sinensis L. Osb. CV. Hamlin (an early sweet orange) and the wild relative Citropsis gilletiana Swing. and Ken. (Gillet's cherry orange), a genus native to Africa, is described. Methodology used to produce these hybrids is outlined. Hybridity was confirmed by analysis of morphology, somatic cell chromosome number, and phosphohexose isomerase (PHI; EC 5.3.1.9) isozyme banding patterns obtained by electrophoresis on horizontal starch gels. This hybrid and other intergeneric somatic hybrids that we have produced are being fieldevaluated for citrus rootstock potential. In-

Received for publication 18 Nov. 1988. Florida Agricultural Experiment Station Journal Series no. 9365. We thank J.L. Chandler and Pan-Chi Lieu for technical assistance. The cost of publishing this paper was defrayed in part by the payment of page charges. Under postal regulations, this paper therefore must be hereby marked advertisement solely to indicate this fact.

'Associate Professor.

${ }^{2}$ Assistant Professor. tergeneric somatic hybridization of plants has been accomplished in very few families. It has been a powerful research tool, 'but thus far there has been little direct application of the technique to plant breeding and cultivar development. The propensity for interspecific hybridization within the genus Citrus and among the genera of the "True Citrus Fruit Tree" subtribal group (Table 1) is remarkable and rare among woody plants (Barrett, 1977; Swingle and Reece, 1967). However, factors such as long reproductive cycle, influence of apomixis and heterozygosity on selection, difficulty with sexual hybrid survival, and complexity of detecting genetic traits have precluded a full understanding of taxonomic relationships and limits to gene transfer within and among Citrus and related genera (Barrett, 1977). The work described herein is a good example of the direct application of biotechnological methods to the attempted solution of agricultural problems as well as to the elucidation of critical genetic questions for perennial plants.

A major goal of traditional plant breeding is the transfer of genes conferring disease resistance or stress tolerance from related wild species into modern high-yielding crop cultivars (Cocking, 1985). This approach is difficult to apply to Citrus breeding (and most other crops) because the majority of related wild species are either difficult or impossible to hybridize with Citrus using traditional crossing methods. The Reed for gene transfer is increasing because urban development of prime agricultural land is forcing agriculture onto less-desirable land, where environmental stress is a greater factor. Moreover, the use of chemicals to control pests and pathogens is being limited or eliminated in many cases to minimize contamination of the environment. Most of the world Citrus industry is a perennial monocultural system composed of a small number of closely related genotypes cultivated in relatively small areas of dense plantings, creating the potential for disaster from a build up of pathogens (Barrett and Rhodes, 1976). The narrow, vulnerable germplasm base of cultivated Citrus necessitates the successful integration of important traits from distant relatives into superior new Citrus cultivars. Further, Citrus is amenable to contemporary techniques of cell culture and gene transfer, thereby providing the opportunity to bypass barriers to sexual hybridization.

\section{Genetic perspectives on intergeneric somatic hybridization of plants}

A wide range of mechanisms prevents successful hybridization between related genera of plants. Barriers to hybridization include genetically controlled gametophytic and sporophytic incompatibility systems (Taylor, 1980), prezygotic mechanisms (e.g., inhibition of pollen germination, inadequate or arrested pollen tube growth), postzygotic mechanisms (e.g., endosperm failure, ploidy imbalance), and somatic incompatibilities (Harms, 1983). It is often difficult to identify the mechanism(s) preventing sexual hybridization in specific cases. However, if this can be achieved, techniques are available to facilitate sexual hybridization (Collins et al., 1984; Sharma and Shivanna, 1986; Williams and DeLautour, 1980; Yamashita, 1987; Yamashita and Tanimoto, 1985). Hybrids produced from such wide combinations are often infertile. In some cases, doubling the chromosome number (sometimes a difficult task) can restore fertility by providing appropriate chromosome partners for normal meiotic pairing. The probability of producing fertile hybrids in this fashion between distant relatives is relatively low.

In contrast, somatic hybridization via protoplasm fusion bypasses the sexual process to

Table 1. Genera of tribe Citrae, subtribe II: $\mathrm{Ci}$ trinae (Citrus fruit trees, three subtribal groups, 13 genera), according to Swingle and Reece (1967) and compatibility with Citrus (Sykes, 1988)

\begin{tabular}{lcc}
\hline \hline & $\begin{array}{c}\text { Sexual } \\
\text { compatibility }\end{array}$ & $\begin{array}{c}\text { Graft } \\
\text { compatibility }\end{array}$ \\
\hline A) Primitive citrus fruit trees & \\
Severinia & & \\
Ple i o s pe r mi u m & - & - \\
Burkillanthus & - & - \\
Limnocitrus & - & - \\
Hesperathusa & - & + \\
B) Near citrus fruit trees & & \\
Citropsis & - & + \\
Atalantia & - & + \\
C) True citrus fruit trees & & + \\
Fortunella & + & + \\
Eremocitrus & + & + \\
Poncirus & & + \\
Clymenia & + & + \\
Microcitrus & + & + \\
Citrus & & + \\
\hline
\end{tabular}

${ }^{2}$ Indicates successful somatic hybridization with Citrus. 
produce allotetraploid (amphidiploid) hybrids. It is an additive process that combines the complete nuclear genomes of both parents; however, in extremely wide combinations, chromosome elimination can occur (Kao, 1977). The potential heterozygosity of somatic hybrids is great, depending on cumulative allelic differences between the contributing parents. Also, in contrast to sexual hybridization, where cytoplasmic (chloroplasts and mitochondria) genome inheritance is predominantly maternal, somatic hybridization allows for cytoplasmic genome contributions from both parents. Additional genetic variability may arise from cytoplasmic and nuclear gene recombination or somaclonal variation (Cocking, 1985).

Successful somatic hybridization has been largely limited to the Solanaceae, the Cruciferae, and, more recently, the Leguminosae (Evans, 1983; Sundburg and Glimelius, 1986; Wright et al., 1987). The lack of efficient protoplasm-to-plant regeneration systems outside these families and somatic incompatibilities between distantly related species (Harms, 1983) have been the predominant limiting factors. Somatic hybrids in the aforementioned families have not been directly useful in the field because they carry negative traits from the wild relative species that reduce agronomic or horticultural performance and harvestable product quality to unacceptable levels. Extensive backcrossing programs are required to eliminate such traits, but frequently such efforts are hampered by low fertility of the somatic hybrids (Cocking, 1985). Another negative factor is the increased ploidy level, which is unsuitable for most breeding programs.

\section{The role of somatic hybridization in Citrus germplasm enhancement and cultivar development}

Citrus scion cultivars, like many fruit and nut trees, are seldom grown on their own roots. Rather, they are almost universally budded onto related, but genetically distinct, genotypes (rootstock) that are better-adapted to a particular environment, resulting in stress tolerance, improved fruit quality, and increased yield. This method of propagation offers a unique advantage for employing new gene transfer methods because it allows genetic improvement of the rootstock without changing the genetic integrity of the scion or marketable fruit characteristics. The majority of chronic problems in citriculture, including susceptibility to biotic and environmental stresses, are influenced or controlled by rootstock.

Adequate resistance to citrus "blight", a rootstock-mediated malady of unknown cause that afflicts commercial Citrus plantings, has not been identified within the genus Citrus. This is a crucial problem for Florida and Brazilian citriculture, as up to 1 million productive trees are lost annually to blight in Florida alone. Successful hybridization of Citrus with related genera offers potential to generate improved blight-resistant material.

The genetic diversity found among Citrus and related genera is profound, but accessi- bility is generally difficult or impossible (Barrett, 1977; Swingle and Reece, 1967). The subtribe Citrinae of the orange subfamily Aurantiodeae (family Rutaceae) has been split into three subtribal groups (Table 1), and there are no existing sexual hybrids among them. For example, Citropsis gilletiana Swing. and M. Ken., a distant relative of Citrus and a member of the "Near Citrus Fruit Tree" subtribal group (Table 1), was identified as an excellent candidate species for Citrus germplasm enhancement. This species is immune to Phytophthora $\mathrm{ci}$ trophthora (Sm. and $\mathrm{Sm}$.), a severe type of foot rot (Swingle and Reece, 1967), and resistant to Radopholus citrophilus Huettle, Dixon and Kaplan, the burrowing nematode (Ford and Feder, 1960). Citropsis gilletiana and several other potentially important' Citrus relatives (e. g., Severinia, Feronia, Swinglea, etc.) are graft-compatible with Citrus, but sexually incompatible, and they are not horticulturally acceptable when used directly as rootstock for Citrus (Swingle and Reece, 1967). Successful hybridization with Citrus may minimize or eliminate problems of inadequate horticultural performance. Fertile intergeneric hybrids would provide new sources of breeding material with unique genetic potential for scion and rootstock improvement programs (Grosser et al., 1988a; 1988b). Intergeneric somatic hybrids may have direct potential as rootstock; however, if backcrossing is required to improve horticultural performance, one or two generations may be sufficient. Therefore, successful somatic hybridization of woody species may provide horticulturally useful, economically important, new combinations of characteristics. Somatic hybridization offers other advantages over traditional breeding methods for Citrus. Most cultivated Citrus types are highly heterozygous hybrids that reproduce apomictically from seed and produce few, if any, zygotic embryos or seedlings because of nucellar (maternal) embryony. Male and/ or female sterility is also sometimes observed. Zygotic seedlings, when produced, are often weak and do not survive. This is perhaps due to the expression of deleterious recessive genes that are masked in the parents (Barrett and Rhodes, 1976; Swingle and Reece, 1967). Such deleterious recessive genes should remain masked and not be expressed in somatic hybrids. Moreover, traits for which expression is controlled by dominant gene systems have a high probability of being expressed in amphidiploid somatic hybrids. For Citrus, these traits include cold hardiness, polyembryony, and resistance to citrus tristeza virus, foot rot (Phytophthora parasitic Dast.), and citrus nematode [Tylenchulus semipenetrans (Cobb)] (Hutchison, 1985).

\section{Previous accomplishments}

Considering the complexity of breeding systems, the lack of knowledge regarding the mechanisms that prevent sexual wide hybridization, and the advancements made in tissue and protoplasm culture in Citrus (Barlass and Skene, 1982; Button and Bornman,
1971; Button and Kochba, 1977; Chaturvedi and Mitra, 1974; Kobayashi et al., 1983; Mitra and Chaturvedi, 1972; Moore, 1985; Ohgawara et al., 1985; Rangan et al., 1969; Starrantino and Russo, 1980; Vardi et al., 1982, 1986), the emphasis of our research has been to develop and implement a routine somatic hybridization system capable of generating somatic hybrids among Citrus and sexually incompatible genera (Grosser et al., 1988a, 1988b).

Protoplasm research involving Citrus species has been limited (as with all woody species), but there are several examples of wholeplant regeneration via somatic embryogenesis from Citrus protoplasts derived from nucellar callus (Kobayashi et al., 1983; Vardi et al., 1982, 1986). The first example of somatic hybridization in Citrus was reported by Ohgawara et al. (1985). This intergeneric somatic hybrid, produced between sexually compatible members of the "True Citrus Fruit Tree" subtribal group, was generated from the fusion of leaf protoplasts of Poncirus trifoliata (L.) Raf. with embryogenic callus protoplasts of Citrus sinemsis CV. Trovita. We have produced a similar hybrid between $P$. trifoliata $\mathrm{CV}$. Flying Dragon and $C$. sinensis CV. Hamlin (Grosser et al., 1988a). This was accomplished by fusing 'Hamlin' protoplasts isolated from a habituated embryogenic suspension culture with 'Flying Dragon' protoplasts isolated from juvenile leaf tissue (Grosser and Chandler, 1987; Grosser et al., 1988a).

The hybrid selection scheme used was based on complementation of the regenerative capability of the 'Hamlin' cell line and the subsequent expression of the trifoliate leaf character of 'Flying Dragon'. Unfused 'Hamlin' protoplasts acted as nurse culture cells and provided the appropriate cell density necessary for heterokaryon survival. The 'Hamlin' line was in culture for more than 4 years. Although protoplasts isolated from this line were amenable to culture and fusion, the capacity for whole-plant recovery was lost (attributed to culture age). The protoplasm culture medium used did not support cell wall resynthesis or mitosis in unfused 'Flying Dragon' leaf protoplasts. Hybrid plants were regenerated via somatic embryogenesis and multiplied organogenically. Hybrid morphology was intermediate to that of the parents and chromosome counts indicated that the hybrids were allotetraploids $(2 n=36)$. Inheritance of malate dehydrogenase (MDH; EC 1.1.1.37) isozymes separated by starch gel electrophoresis was used to verify hybrid identity further. More than 200 plants have been produced, and many of these have been budded and entered into field trials to evaluate the potential of this hybrid as a rootstock for Citrus.

Using a modification of this system, we have also produced $>150$ somatic hybrid plants between the sexually incompatible genera Severinia disticha (Blanco) Swing. (the Philippine box-orange) and C. sinensis CV. Hamlin (Grosser et al., 1988b). These genera are distantly related and belong to different subtribal groups (Table 1). Suc- 
cessful hybridization of these genera was accomplished by fusing embryogenic suspension culture-derived protoplasts of 'Hamlin' with seedling epicotyl callus-derived protoplasts of S. disticha. Seedling epicotyl callus is nonembryogenic, and, in contrast with Citrus embryogenic callus, is grown on a highauxin medium. Therefore, only somatic hybrid fusion products were capable of producing viable embryos in this culture system. These hybrids also exhibited morphology intermediate to that of the parents and were allotretraploid. Along with the expression of morphological characters from both parents, further verification of hybridity was obtained from electrophoretic analyses of phosphoglucomutase (PGM; EC 2.7.5.1) isozymes. To the best of our knowledge, this was the first example of somatic hybrid plants produced among sexually incompatible genera of woody plants and between the "Primitive Citrus" and "True Citrus" subtribal groups. Production of this hybrid indicates that somatic hybridization may provide a means of bypassing barriers to sexual hybridization to access previously unavailable, but desirable, Rutaceous germplasm.

\section{Somatic hybrid selection}

The key to successful somatic hybridization is having an efficient selection scheme to identify and isolate the desired fusion products. Following the chemical fusion of protoplasts, the freqtiency of heterokaryon formation is generally low (in the range of $1 \%$ to $10 \%$ ). Hybrid cells must be able to compete with unfused parental cells, and there must be a system to regenerate, identify, and separate hybrid plants. Many methods have been devised to accomplish this in various systems, and excellent reviews are available (Collins et al., 1984; Evans,, 1983). Based on the production of the previously discussed somatic hybrids, we have devised a flexible system that restricts whole-plant recovery to somatic hybrid material. The system takes advantage of differences in metabolic requirements and in morphogenetic ability of cells from different explant sources (somatic embryogenesis vs. organogenesis).

Habituated $C$. sinensis callus with embryogenic potential can be grown on growth regulator-free liquid or solid medium. If maintained in culture for a long period of time (usually 2 or more years), the capacity for embryogenesis is maintained, but the capability to recover whole plants from recovered embryos can be either greatly diminished or eliminated. Suspension cultures of such tissue (on a 2-week subculture cycle) are a superior, high-yielding source of protoplasts already adapted to liquid culture. As demonstrated (Grosser et al., 1988a, 1988b), unfused habituated C. sinensis protoplasts act as nurse cells to provide the cell densities necessary for adequate plating efficiency. To make the selection scheme work, the source of Citrus relative protoplasts must come from an explant that has growth regulator requirements for successful culture. Protoplasts isolated from such explants cannot resynthesize cell walls nor undergo mi- tosis in growth regulator-free protoplasm culture media. Following fusion, unfused protoplasts of the Citrus relative die or disintegrate; however, when the protoplasts of the Citrus relatives are fused with habituated C. sinensis protoplasts, complementation occurs, thereby restoring the capacity for whole-plant recovery from resulting heterokaryons.

We have already described two proven sources of such protoplasts-leaves (Grosser and Chandler, 1987; Grosser et al., 1988a) or callus tissue initiated from seedling leaf, epicotyl, or hypocotyl explants (Grosser et al., 1988b) and grown on a high-auxin medium. Leaves provide a high-yielding source of protoplasts (Grosser and Chandler, 1987); but, in some cases, they may contain secondary metabolizes that could interfere with successful protoplasm culture. Stem or leaf callus, consisting of undifferentiated cells committed to mitosis, are an alternative source. The production of secondary metabolizes by such cells appears to be reduced. Also, there may be a carry-over of endogenous auxin in protoplasts isolated from such callus that could possibly enhance plating efficiency following fusions.

Adequate yields of protoplasts that are amenable to fusion can be isolated from auxingrown callus of many Citrus relatives (unpublished data), including Citropsis gilletiana. It is also beneficial if the explant tissue has the capacity to undergo adventitious bud induction and shoot formation (organogenesis) when placed on media containing high levels of the synthetic cytokinin benzyladenine. This characteristic increases the possibility of regenerating whole plants following fusions (Grosser et al., 1988 b), and it may provide a means to multiply resulting hybrid plants for field evaluation (Grosser et al., 1988a, 1988b).

Numerous distinct morphological differences among Citrus and its wild relatives simplify the identification of somatic hybrid plants (Fig. 1). Poncirus develops trifoliate leaves; this is a dominant trait that is expressed in both sexual and somatic Citrus $\times$ Poncirus hybrids (Grosser et al., 1988a; Ohgawara et al., 1985). Severinia exhibits red pigmentation in new growth, and Citrus has a winged petiole; both of these traits were expressed in the somatic hybrid (Grosser et al., 1988 b). Likewise, Citropsis gilletiana has a hi-winged pentafoliate leaf that facilitated identification of Citrus $\times$ Citropsis somatic hybrids.

\section{Production and characterization of Citrus sinensis $\times$ Citropsis gilletiana somatic hybrid plants}

The only source of Citropsis gilletiana plant material available for somatic hybridization with C. sinensis was a juvenile seedling tree, $\approx 3 \mathrm{~m}$ high. Citropsis gilletiana protoplasts were isolated either directly from sterilized juvenile leaves or from nonembryogenic calIus tissue initiated from juvenile stem sections using methods already described (Grosser and Chandler, 1987). Citropsis protoplasts from both sources were chemically fused with C. sinensis $\mathrm{CV}$. Hamlin protoplasts isolated from a habituated embryogenic suspension culture and cultured as described by Grosser et al. (1988a, 1988b). Numerous somatic hybrid embryos (> 250) of normal morphology were recovered from fusions involving Citropsis leaf protoplasts. Some embryos were produced directly on the liquid medium, but most arose from calli that had been transferred to solid medium. About $50 \%$ of these embryos produced shoots when cultured on a medium containing $1.0 \mathrm{mg} \mathrm{GA} /$ liter (gibberellic acid) and $15 \mathrm{mg}$ coumarin/ liter. A few embryos that produced both roots and shoots were transferred directly to pots containing a commercial soil mixture. The remaining majority of shoots formed functional roots when cultured on a half-strength MT basal medium (Murashige and Tucker, 1969) containing $0.5 \mathrm{~g}$ neutralized activated

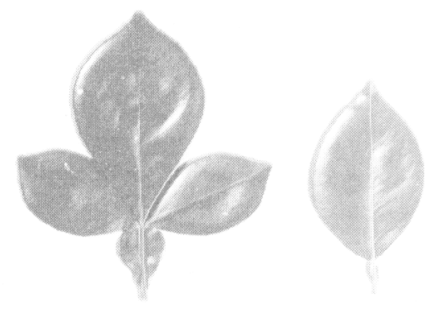


charcoal/liter. As of Aug. 1988, > 135 plants were growing vigorously in soil and were ready for [he evaluation of this hybrid as a potential Citrus rootstock.

Recovery of somatic hybrid embryos was much less efficient from fusions involving Citropsis callus protoplasts than with leaf protoplasts. No embryos were recovered directly on liquid medium, but 13 embryos were recovered from calli that had been transferred to solid medium. Four of these embryos produced shoots when cultured on the germination medium, and they rooted readily when cultured on rooting medium. These results contrast with the generation of the $C$. sinensis $\times$ Severinia disticha somatic hybrid, in which plants were recovered only from fusions involving $S$. disticha callus protoplasts. Fusions of $C$. sinensis with $S$. disti$d a$ leaf protoplasts did not result in the recovery of hybrid plants.

Although the morphology of the first leaves produced by putative regenerated hybrid plants was quite variable (Fig. 1), it eventually stabilized to an intermediate trifoliate form with an elongated winged petiole. All of the regenerated plants appeared uniform. Hybrid plants were vigorous and produced well-developed root systems. Cytological evaluation of 10 randomly selected somatic hybrid plants, using the method described by Grosser et al. (1988a), revealed the allotetraploid chromosome number of 36 . Additional verification of somatic hybrid identity was obtained from PHI isozyme analysis. PHI isozymes were separated using horizontal starch gel electrophoresis with constant current of 60 $\mathrm{mA}$ for $3 \mathrm{hr}$ at $6 \mathrm{C}$ and the $\mathrm{pH} 5.7$ histidinecitrate buffer system of Cardy et al. (1981). The enzyme activity stain recipe was from Vallejos (1983). Both Citrus sinensis and Citropsis gilletiana are heterozygous at the PHI locus and display a three-banded pattern typical of a dimeric enzyme. However, these two parents can be distinguished easily because the protein products specified by the Citropsis gilletiana alleles migrate faster than those of $C$. sinensis. The zymogram produced by the somatic hybrid plants revealed

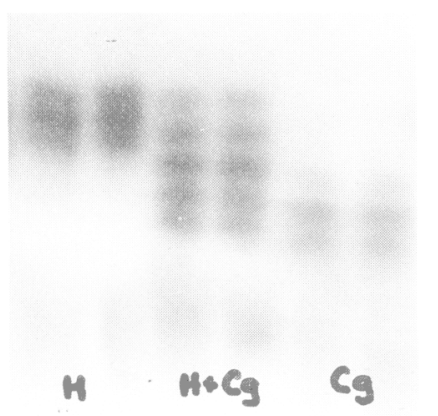

Fig. 2. Starch gel electrophoresis of PHI isozymes. The photo of the zymogram demonstrates a complementary banding "pattern in somatic hybrid plants $(\mathrm{H}+\mathrm{Cg})$ produced between 'Hamlin' sweet orange $(\mathrm{H})$ and Citropsis gilletiana $(\mathrm{Cg})$. a more complex, complementary pattern that showed the presence and activity of alleles unique to each of the contributing parents (Fig. 2). To the best of our knowledge, these C. sinensis $\times$ Citropsis gilletiana somatic hybrid plants are the first example of viable hybrids produced" between members of the "Near Citrus Fruit Tree" and the "True Citrus Fruit Tree" subtribal groups, and only

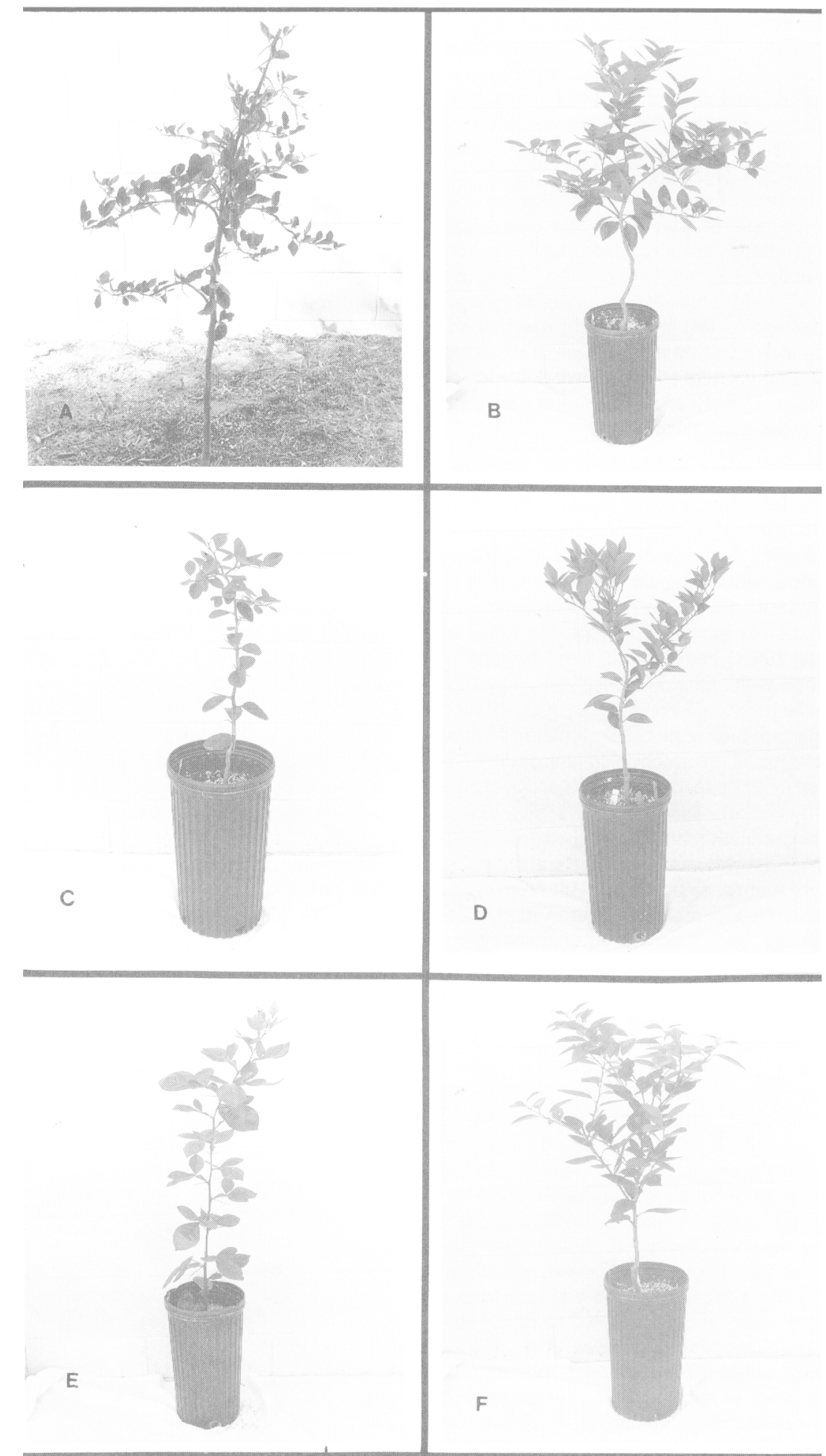

Fig. 3. Intergencne somatic hybrid trees; ungrafted, and as rootstock budded with 'Valencla' sweet orange scion: Citrus sinensis CV. Hamlin + Poncirus trifoliata $\mathrm{CV}$. Flying Dragon somatic hybrid (A) ungrafted and (B) grafted; Citrus sinensis $\mathrm{CV}$. Hamlin $\times$ Severinia disticha somatic hybrid (C) ungrafted and (D) grafted; and Citrus sinensis Cv. Hamlin $\times$ Citropsis gilletiana somatic hybrid (E) ungrafted and (F) grafted. 
quire the same evaluation process that sexual hybrids would undergo to determine their suitability as rootstock. Specifically, resistance/tolerance of biotic and environmenta stresses and horticultural characteristics (nursery and field performance) must be evaluated and compared with current standard cultivars. This is an unavoidable, timeconsuming requirement that is necessary before these hybrids can be released or recommended to the industry.

Although the hybrids are tetraploid, they possess. great potential as breeding parents that may serve as "genetic bridges" between Citrus and related genera. Further hybridizations could be undertaken using some of the uncommon, naturally occurring Citrus tetraploids as suitable parents. The production of monoploid $(n=2 x=18)$ plants from anther or microspore cultures originating from somatic hybrids is another alternative approach to using these unique genetic lines in Citrus breeding at the diploid level. Research on methods to accomplish this on a routine basis is necessary; however, the probability of successful monoploid production seems great, considering the amenability of Citrus tissue. Any use of these hybrids in sexual breeding schemes depends, of course, on their capability to reach maturity and produce flowers that possess some degree of fertility.

The difficulties that limit Citrus breeding by standard methods (i. e., sterility, apomixis, prolonged juvenility, and possible inbreeding depression) also limit meaningful genetic studies with Citrus. However, somatic hybrids may provide unique opportunities to study genetic control of traits of economic significance. By creating specific combinations of tolerant and susceptible parental types and studying the behavior of somatic hybrids when challenged, the additivity, or dominance/recessivenessj of these genetic traits could be determined. Studies of meiosis and relative fertility of flowering somatic hybrids can yield valuable information regarding chromosome homology among Citrus and related genera that may prove useful in attempts to describe valid taxonomic relationships of members of the Rutaceae.

Somatic hybridization is an additive process and does not involve recombination and segregation of traits in progeny. Each hybridization results presumably in only one hybrid genotype. The number and genetic diversity of hybrids available for evaluation and selection should be increased to maximize the probability of creating and selecting genetically and horticulturally superior hybrids with this technique. This can be accomplished by increasing the number and diversity of parental combinations used to create somatic hybrids. Future work should include efforts to create somatic hybrids using other Citrus relatives (including other species of Citropsis and Severinia) and Citrus species other than $C$. sinensis as parents. In this manner, the untapped genetic potential that resides within genera related to Citrus may be exploited.

\section{Literature Cited}

Barlass, M. and K.G.M. Skene. 1982. [n vitro plantlet formation from Citrus species and hybrids. Scientia Hort. 17:333-341.

Barrett, H.C. 1977. Intergeneric hybridization of Citrus and other genera in citrus cultivar improvement. Proc. Intl. Soc. Citricult. 2:586589.

Barrett, H.C. and A.M. Rhodes. 1976. A numerical taxonomic study of affinity relationships in cultivated citrus and its close relatives. Syst. Bet. 1:105-136.

Button, J. and C.H. Bornman. 1971. Development of nucellar plants from unpollinated and unfertilized ovules of the Washington naval orange in vitro. J. S. Afr. Bet. 37:127-134.

Button, J. and J. Kochba. 1977. Tissue culture in the citrus industry, p. 70-92. In: J. Reinert and V.P.S. Bajaj (eds.). Applied and fundamenta aspects in plant, cell, tissue and organ culture. Springer-Verlag, Berlin.

Cardy, B. J., C.W. Stuber, and M.M. Goodman. 1981. Techniques for starch gel electrophoresis of enzymes from maize(Zea mays L.). North Carolina State Univ., Raleigh. Inst. Stat. Mimeo. Serv. 1317.

Chaturvedi, H.C. and G.C. Mitra. 1974. Clonal propagation of Citrus from somatic callus cultures. HortScience 9:1 18-120.

Cocking, E.C. 1985. Somatic hybridization: Implications for agriculture, p. 101-113. In: M. Zaidin (ed.). Biotechnology in plant science. Academic, Orlando, Fla.

Collins, G. B., N.L. Taylor, and J.W. Deverna. 1984. In vitro approaches to interspecific hy bridization and chromosome manipulation in crop plants, p. 323-383. In: J.P. Gustafson (ed.). Gene manipulation in plant improvement. 16th Stadler Genet. Symp. Plenum, New York.

Evans, D.A. 1983. Protoplasm fusion, p. 291-321. In: D.A. Evans, W.R. Sharp, P.V. Ammirato, and Y. Yamada (eds. ). Handbook of plant cell culture. Macmillan, New York.

Ford, H.W. and W.A. Feder. 1960. Citropsis gilletiana, a citrus relative resistant to the burrowing nematode in laboratory tests. Proc. Fla. State Hort. Soc. 73:60-64.

Grosser, J.W. and J.L. Chandler. 1987. Aseptic isolation of leaf protoplasts from Citrus, Poncirus, Poncirus $\times$ Cirrus hybrids and Severinia for use in somatic hybridization experiments Scientia Hort. 31:253-257.

Grosser, J. W., F.G. Gmitter, and J.L. Chandler. 1988a. Intergeneric somatic hybridization of Citrus sinensis Cv. Hamlin and Poncirus tnfoliata CV. Flying Dragon. Plant Cell Rpts. 7:58

Grosser, J. W., F.G. Gmitter, and J.L. Chandler. 1988b. Intergeneric somatic hybridization of sexually incompatible woody species: Citrus sinensis and Severinia disticha. Theor. Applied Genet. 75:397-401.

Harms, C.T. 1983. Somatic incompatibility in the development of higher plant somatic hybrids. Quart. Rev. Biol. 58:325-353.

Hutchison, D.J. 1985. Rootstock development screening and selection for disease tolerance and horticultural characteristics. Fruit Var. J. 39:2125 .

Kao, K.N. 1977. Chromosomal behavior in somatic hybrids of soybean-Nicomo-ra glauca. Mol. Gen. Genet. 150:225-230.

Kobayashi, S., H. Uchimaya, and I. Ikeda. 1983. Plant regeneration from 'Trovita' orange protoplasts. Jpn. J. Breeding 33: 119-122.

Mitral, G.C. and H.C. Chaturvedi. 1972. Embryoids and complete plants from unpollmated ovaries and from ovules of in vitro grown emasculated flower buds of Citrus spp. Bul. Torrey
Bot. Club 99:184-189.

Moore, G.A. 1985. Factors affecting in vitro $\mathrm{cm}$ bryogenesis from underdeveloped ovules of mature citrus fruits. J. Amer. Soc. Hort. Sci. 110:66-70.

Murashigc, T. and D.P.H. Tucker. 1969. Growth factor requirements of citrus tissue culture. Proc. First Intl. Citrus Symp. 3:1155-1161.

Ohgawara, T., S. Kobayashi, E. Ohgawara, H. Uchimaya, and S. Ishii. 1985. Somatic hybrid plants obtained by protoplasm fusion between Citrus sinensis and Poncirus trifoliata. Theor. Applied Genet. 71:1-4.

Poopathy, V. 1986. Oranges from the wilds. News Straits Times (Malaysia). 13 Nov.

Rangan, T. S., T. Murashige, and W.P. Bitters. 1969. In vitro studies of zygotic and nucellar embryogenesis in Citrus. Proc. First Ind. Citrus Symp. 1:225-229.

Sharma, N. and K.R. Shivanna. 1986. Treatment of the stigma with an extract of a compatible pistil overcomes self-inwmpatibility inPetunia. New Phytol. 102:443-447.

Starrantino, A. and F. Russo. 1980. Seedlings from underdeveloped ovules of ripe fruits of polyembryonic citrus cultivars. HortScience 131:253258

Sundburg, E. and K. Glimelius. 1986. A method for production of interspecific hybrids within Brassicae via somatic hybridization, using resynthesis of Brassica napus as a model. Theor. Applied Genet. 43:155-162.

Swingle, W.T. and P.C. Reece. 1967. The botany of citrus and its wild relatives, p. 190430. In: W. Reuther, L.D. Batchelor, and H.J. Webber (eds.). The citrus industry. vol. 1. Univ. of California Press, Berkeley.

Sykes, S.R. 1988. Overview of the family Rutaccac, p. 93-100. In: R.R. Walker (ed.). Citrus breeding workshop. CSIRO, Melbourne, Australia.

Taylor, N.L. 1980. Clovers, p. 261-272. [n: W.R. Fehr and H.H. Halley (eds.). Hybridization of crop plants. Amer. Soc. Agron. and Crop Sci. Amer., Madison, Wis.

Vallejos, C.E. 1983. Enzyme staining activity, p. 469-516. In: S.O. Tanksley and T.J. Orton (eds.). Isozymes in plant genetics and breeding. part A. Elsevier, Amsterdam.

Vardi, A., D.J. Hutchison, and E. Galun. 1986. A protoplasm-to-tree system in Microcitrus based on protoplasts derived from a sustained embryogenic callus. Plant Cell Rpts. 5:412-414.

Vardi, A., P. Spiegel-Roy, and E. Galun. 1982. Plant regeneration from citrus protoplasts: Variability in methodological requirements among cultivars and species. Theor. Applied Genet. 62:171-176.

Williams, E.G. and G. DeLautour. 1980. The use of embryo culture with transplanted nurse endosperm for the production of interspecific hybrids in pasture legumes. Bet. Gaz. 141:252257.

Wright, R. L., D.A. Somers, and R.L. McGraw. 1987. Somatic hybridization between birdsfoot treefoil (Lotus corniculatus L.) and L. coimbrensis Wind. Theor. Applied Genet. 75:151156.

Yamashita, K. 1987. Studies on self-incompatibility of Hassaku (Citrus hassaku Hort. ex Tanaka): 1. Some fundamental experiments focusing on the significance of stigmas in incompatible reactions. J. Jpn. Soc. Hort. Sci. 56:268-273. Yamashita, K. and S. Tanimoto. 1985. Studies on self-incompatibility of Hassaku (Citrus hassaku Hort. ex Tanaka): H. Glycoprotein composition in pistils soon after self-pollination, and several trials to overcome self-incompatibility. J. Jpn. Soc. Hort. Sci. 54:178-183. 